\title{
Minha casa é aqui dentro: o sentido social do arranjo da casa de Amanã ${ }^{1}$
}

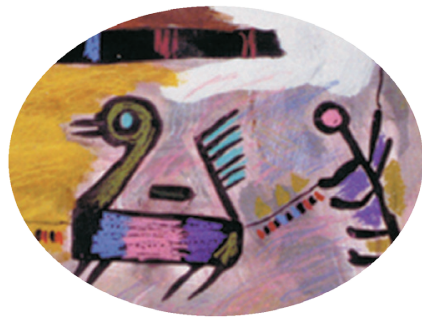

Thatyana de Soura Marques*

\section{Resumo}

Esta pesquisa tem como objetivo compreender os elementos e condições para que um espaço arquitetônico adquira o status de lar. Inicialmente, tinha como foco os objetos que compõem os ambientes da casa. Do ponto de vista arquitetônico, ao conceber uma casa, deve-se pensar no que colocar lá dentro, onde e como colocar os objetos que compõem o espaço. Essa perspectiva baseia-se no conceito de arranjo. Os sujeitos da pesquisa - moradores da localidade Boa Esperança, na Reserva de Desenvolvimento Sustentável Amanã (RDSA) e a permanência em suas casas me fizeram ampliar a perspectiva arquitetônica. O trabalho de campo compreendeu na estada da morada de um grupo doméstico da comunidade Boa Esperança, no uso de entrevistas gravadas e no registro fotográfico. A pesquisa revelou que o sentido social do arranjo é possibilitar a interação entre os residentes e não residentes da casa. Mas o que torna uma casa de moradia para aqueles que a residem é estar inserido nesse lugar: o lago Amanã. "Minha casa é aqui dentro" resume o sentimento de pertencimento à região, que é o elemento que possibilita que esse espaço arquitetônico adquira o status de lar. Aqui dentro é a relação com o histórico de ocupação, com o parentesco, com as atividades produtivas, com o viver em comunidade e com a dinâmica ambiental.

Palavras-chave: casa; objetos; pertencimento.

* Doutoranda do Programa de Pós-Graduação Sociedade e Cultura da Amazônia (PPGSCA) na Universidade Federal do Amazonas (Ufam). Pesquisadora do Instituto de Desenvolvimento Sustentável Mamirauá (IDSM). E-mail: thatyana@mamiraua.org.br 


\begin{abstract}
This research aims to understand the factors and conditions for which an architectural space acquires the status of home. Initially, he focused on the objects that make up the rooms of the house. From the architectural point of view, when designing a home, you should think about what to put in there, where and how to place the objects that make up the space. This perspective is based on the concept of arrangement. The research subjects - residents of the locality Good Hope in Amana Sustainable Development Reserve (RDSA) and stay in their homes made me expand the architectural perspective. The fieldwork comprised the residence address of a domestic group of community Good Hope, in the use of recorded interviews and photographic record. The research revealed that the social meaning of the arrangement is to enable the interaction between residents and non-residents of the house. But what makes a house a home for those who reside in this place is to be inserted: Lake Amana. "My home is here 'summarizes the sense of belonging to the region, which is the element that allows this architectural space acquires the status of home. In here is the link with the history of the occupation with the relationship with the productive activities, with community living and the environmental dynamics.
\end{abstract}

Keywords: house; objects; belonging.

\title{
Introdução
}

Onde por acaso eu me encontro é meu "domicílio"; onde tenho intenção de ficar é a minha "residência"; de onde venho e para onde quero retornar é o meu "lar". No entanto, lar não é apenas o local - minha casa, meu quarto, meu jardim, minha cidade - mas tudo o que ele simboliza. O caráter simbólico da noção de "lar" é emocionalmente evocativo e difícil de descrever. Lar significa coisas diferentes para diferentes pessoas. Significa, é claro, [...] coisas familiares para uso diário, costumes, hábitos pessoais - em suma, um estilo peculiar de vida, composto de pequenos elementos importantes e queridos (SHUTZ apud WAGNER, 1979: 291). 
O presente estudo tem como objetivo compreender os elementos e condições para que um espaço arquitetônico adquira o status de lar.

Como arquiteta, defendia que, ao idealizar o projeto de uma casa, devia-se pensar em quais materiais empregar na construção, o que colocar no seu interior (objetos e mobiliário) e qual a disposição, além de refletir acerca de como seus usuários se relacionariam com esse espaço. Essa perspectiva adotada tinha como base teórica o conceito de arranjo.

Para Baudrillard (2006), a estrutura do arranjo está relacionada com a disposição e a combinação dos objetos de forma a obter um conjunto funcional capaz de comunicar valores sociais. A disposição espacial, por exemplo, da mobília de uma casa de moradia deve estar disposta de modo a possibilitar o funcionamento do arranjo. "Neste espaço privado, cada móvel, cada cômodo por sua vez interioriza sua função e reveste-lhe a dignidade simbólica: completando a casa inteira a integração das relações pessoais no grupo semifechado da família" (BAUDRILLARD, 2006: 22). Portanto, a estrutura do arranjo revela os aspectos organizacionais da cultura que a gerou.

Os sujeitos da pesquisa - moradores da localidade Boa Esperança, na Reserva de Desenvolvimento Sustentável Amanã (RDSA)² - e a permanência em suas casas ampliaram o ponto de vista inicial:

O equívoco de enfoque cometido por Zevi e por tantos outros pensadores deriva do fato de pretenderem definir arquitetura apenas a partir dos componentes físicovisuais do objeto arquitetônico, negligenciando aquilo que consideramos mais importante, que é a dimensão antropológica. $\mathrm{Na}$ dimensão antropológica residem os aspectos relevantes da manifestação, que são o propósito existencial e suas relações com a forma edificada (SILVA, 1994: 92).

Por conta do contexto e da especificidade que esses moradores se inserem, há uma necessidade de conhecimento acerca do ambiente natural, da história de ocupação desse território e das suas atividades econômicas desenvolvidas pelos moradores como forma de compreender o sistema de arranjo ali disposto e, consequentemente, o significado dessa casa. 


\section{O cenário}

A Reserva Amanã está localizada na região do interflúvio dos rios Negro e Japurá, e conectada à área da RDS Mamirauá e Parque Nacional do Jaú, formando, assim, um enorme bloco de florestas protegidas. A paisagem natural de Amanã

apresenta um imenso mosaico de ambientes muito representativos das mais importantes paisagens amazônicas. Existe uma imensa extensão de terra firme de ambos os lados do lago Amanã, cada qual com distintos aspectos geomoforlógicos e perfis de relevo. Há uma porção menor de várzea a sudoeste e ao sul do lago, e outra porção menor de igapós em suas margens. [...] Importantes representantes da flora e da fauna das matas alagadas e não alagadas da Amazônia podem ser encontradas em Amanã, alguns deles oficialmente listados como ameaçados ou vulneráveis, vivendo ainda em alto grau de conservação. As populações de pirarucus, jacarés, botos, peixes-boi, ariranhas, onças, queixadas, gaviões-reais e muitos outros vertebrados são proverbiais, e sua abundância ainda é relativamente alta quando comparada a outras porções do território naquela parte da Amazônia. Grandes estoques de recursos florestais madeireiros e não madeireiros são encontrados no interior da reserva (QUEIROZ, 2005: 248).

Conforme o último Censo Demográfico realizado na RDSA (ainda em desenvolvimento), a população de moradores e de usuários é de 3.653 pessoas, distribuídos em 612 domicílios e 84 localidades. Essa população humana está mais concentrada em torno do lago Amanã, que é um dos maiores da região amazônica com aproximadamente $45 \mathrm{~km}$ de comprimento, e 2 a 3 quilômetros de largura, e em ambos os lados do lago existe uma imensa extensão de terra firme (QUEIROZ, 2005). "O lago Amanã desempenha um papel importante no processo de ocupação humana da área da RDSA, por ser via de acesso a outros cursos de água através dos quais é possível fazer a comunicação com o rio Negro e o rio Japurá” (ALENCAR, 2007: 6). 


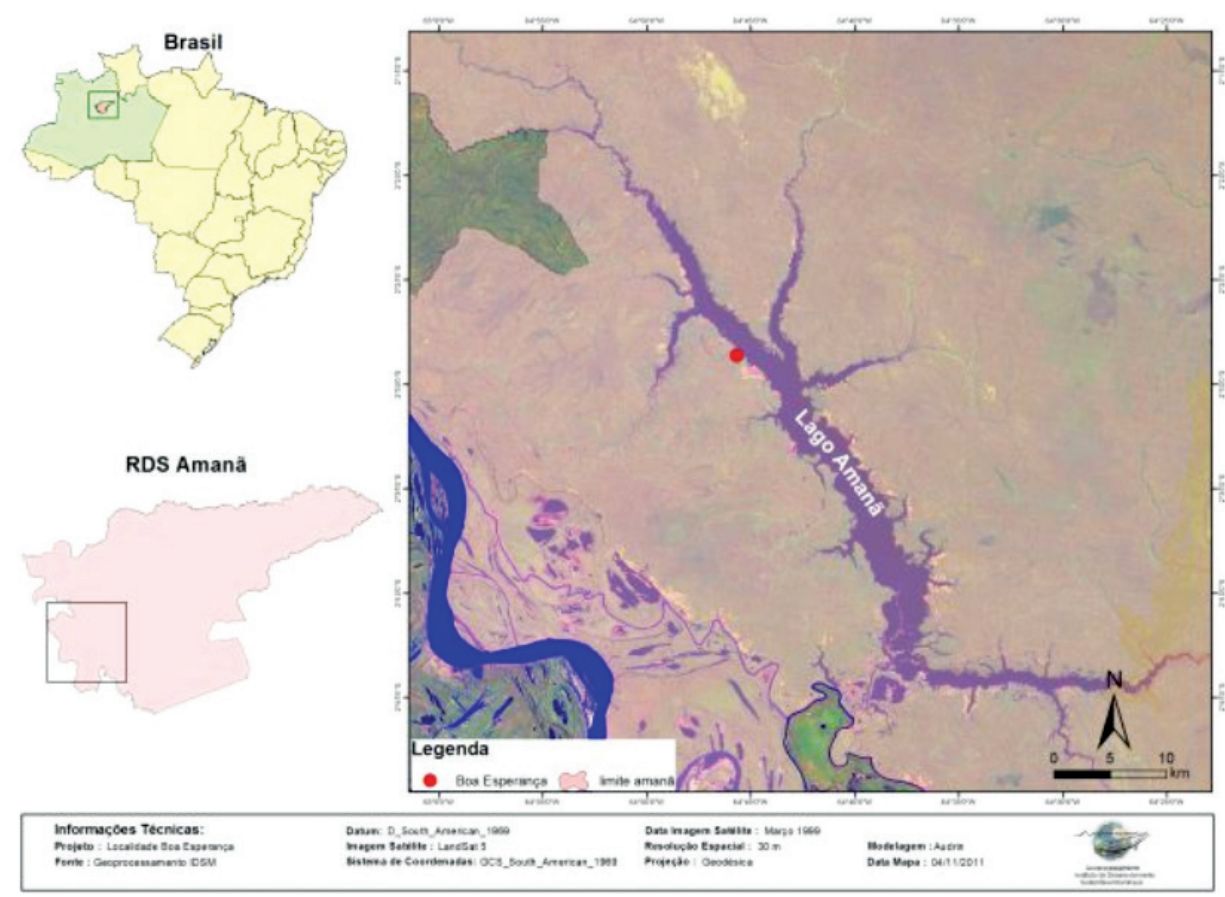

Figura 1 - Área de estudo.

Os elementos que hoje representam o cenário são fruto de uma história de ocupação vinculada aos tipos de produção econômica que predominaram na região (ALENCAR, 2007).

A mobilidade na RDS Amanã, até meados dos anos 60, foi uma característica marcante do processo de ocupação da região, resultado de uma economia baseada no extrativismo de produtos naturais que se encontravam dispersos por uma extensa área geográfica. A ocupação humana da região do lago Amanã ocorreu principalmente nas áreas de terras firmes, onde se situavam as colocações que serviam de base de apoio para aqueles que trabalhavam na extração da seringa, da sorva e na coleta da castanha.

Com o declínio da produção econômica centrada no extrativismo vegetal, a partir dos anos 60 do século 20, a ação da Igreja Católica foi decisiva para estimular uma nova configuração do espaço e de uso dos recursos naturais:

Nos anos 60 a ação da Igreja Católica através da Prelazia de Tefé, do Departamento MEB - Tefé e da Coordenação 
de Pastoral e Paróquias da Prelazia de Tefé, iniciou ações voltadas para a melhoria das condições de vida da população ribeirinha. Estas ações resultaram na formação de unidades demográficas, as 'comunidades', porque estimulou as famílias que viviam dispersas e isoladas a se juntarem para formarem pequenos povoados (ALENCAR, 2007: 44).

Essa nova proposta implicava na agregação das famílias, marcando, assim, uma ruptura na forma de ocupação do espaço a fim de poder buscar soluções para problemas comuns, e possibilidade de ajuda mútua em situações de dificuldade (ALENCAR, 2007):

[...] na concepção local quando se fala em comunidades está se falando de um conjunto de pessoas que partilham um certo território, que realizam ações conjuntas e possuem uma forma de representação política representada pela figura do presidente da comunidade. A própria distribuição espacial das casas, a regulamentação das formas de acesso aos recursos existentes no território comum, a inexistência de divisões territoriais ou cercas demarcando a separação entre as casas é uma característica ressaltada na concepção local de comunidade. Mas a residência não é suficiente para inserir um indivíduo ou família numa comunidade. O que define, ressaltamos, é a participação (ALENCAR, 2007: 48).

A participação e o grau envolvimento do indivíduo com as implicações da nova configuração do espaço constituem o traço marcante que remete ao sentimento de pertencimento, de fazer parte deste ou daquele grupo social.

No final dos anos 90, ocorrem novas mudanças - os ribeirinhos passam a ser residentes de uma unidade de conservação:

[...] a criação da Reserva Amanã está intimamente interligada com sua vizinha, a Reserva de Desenvolvimento Sustentável Mamirauá. Foi durante a V Assembléia Anual de Moradores e Usuários da Reserva Mamirauá, em 1996, na presença de representantes da população local de Mamirauá, de representantes de várias entidades e organizações de base regionais, de autoridades locais, e de representantes do Ipaam, que lideranças da população da região do lago 
Amanã manifestaram seu desejo de que naquele local fosse criada uma reserva em moldes similares àqueles da Reserva Mamirauá. Este foi um acontecimento fundamental para deflagrar a elaboração de uma proposta formal de criação da Reserva Amanã (QUEIROZ, 2005: 247).

Participação, engajamento político, frutos de um movimento social que iniciou com as ações da Igreja, e que se aliou ao interesse em formalizar a preservação ambiental, essencialmente os lagos de pesca. Modelo este que:

[...] reforçou o ideal de coletividade e introduziu um novo sentido de identidade às populações locais, as quais foram convocadas a desenvolver atividades capazes de garantir o uso sustentado e a preservação dos recursos naturais, e a participar do processo de ordenamento do território e de definição das regras de uso desses recursos (ALENCAR, 2007: 116).

A "vida em comunidade está associada a mudanças significativas na vida social e nas estratégias de produção econômica das famílias” (ALENCAR, 2007: 51). A atividade de agricultura é o elemento da realidade da vida cotidiana dos moradores de Amanã e que direciona os afazeres domésticos e as relações de sociabilidade.

Ser agricultor é como os grupos domésticos se identificam. É a principal atividade econômica que tem como foco a produção e comercialização da farinha de mandioca, além de ser um item essencial de consumo interno do grupo doméstico. A agricultura na RDSA é

[...] do tipo itinerante, com manejo baseado no sistema de derruba e queima, seguido de pousio. Há rotatividade de solos e de cultivos. Os agricultores derrubam a floresta ("mata virgem" ou capoeira), queimam o material derrubado, incorporando os nutrientes no solo, e em seguida fazem os plantios [...] A área então é abandonada e deixada em pousio para que se estabeleça a regeneração natural, e os agricultores transferem seus roçados para outro terreno (PEREIRA et. al., 2006: 14). 
A organização social do grupo doméstico visa atender as demandas, inicialmente, de consumo daqueles que coabitam o mesmo espaço - a casa. Sob a autoridade do casal, os membros da casa organizam as tarefas domésticas que estão relacionadas ao sistema sazonal de cheia e seca dos rios e às atividades que este ambiente natural e social impõe.

\section{Conceber a casa na comunidade}

A relação histórica com o local e a distância para as áreas agrícolas são o que os moradores justificam para o estabelecimento da casa em uma comunidade. Sua construção envolve a participação ativa dos residentes e não residentes da casa. Podem ser membros do grupo parental (pai, filho ou irmão) ou de compadrio.

O primeiro passo é identificar na mata as árvores que serão serradas e as espécies madeireiras para cada elemento construtivo. Após a seleção, o dono da casa paga o serrador para ir retirar a madeira. Geralmente, este pagamento ocorre do dinheiro proveniente dos benefícios sociais, como Cartão Cidadão e Bolsa Família. Com a venda da farinha de mandioca ao patrão local, por meio do aviamento, ele adquire os itens industrializados - telhas, pregos e combustível.

O sistema de aviamento é a forma predominante de comércio para a produção agrícola, assim como na Reserva Mamirauá (LIMA, 2006). Este sistema caracteriza-se pelo fornecimento de mercadorias a crédito, que podem ser desde itens alimentares até como o próprio material de construção (telhas e pregos), e que são posteriormente pagas com o produto (farinha). Com a madeira serrada, a telha e os pregos, o morador contrata o carpinteiro para dar início à construção.

Com a finalidade de exemplificar, apresentamos a seguir o processo de construção de uma casa erguida na mesma comunidade, no ano de 2009. Essa casa tinha como planejamento inicial acomodar um casal, dois filhos adultos e três crianças. A casa que antes abrigava esse grupo doméstico era considerada pequena, devido ao número de filhos, e também era antiga, por apresentar goteiras e algumas madeiras apodrecidas. Eles relataram que há algum tempo estavam guardando dinheiro para esta construção e que, naquele momento, poderiam construí-la. 
A antiga casa foi derrubada e em seu lugar a nova foi erguida. A intenção era ter $6 \mathrm{~m}$ por 14 metros de fundos, com sala, 4 quartos, 2 cozinhas e uma área para banho. O processo construtivo para erguer os elementos estruturantes dessa casa durou cerca de três dias. Inicialmente, perfuraram o solo a fim de fincar os barrotes. ${ }^{3}$ Os barrotes de uma casa têm de ser de madeiras resistentes e duráveis, como por exemplo, as espécies itaúba, jacareúba e acapu. Nessa casa, foram utilizadas oito peças de madeiras itaúba e acapu para sustentar a casa. Pelo fato de o terreno apresentar desnível, os barrotes tinham alturas diferentes. Ao serem fincados no chão suas extremidades ficam alinhadas com os demais.

A segunda peça de madeira a ser encaixada no barrote é a travessa ou linha. As quatro linhas de madeira tamacoré nivelam a casa num plano reto. Em seguida, os pinos foram erguidos - oito pinos de madeira castanha-de-rato marcam a altura menor da casa. Foram necessárias dezessete peças de madeira tamacoré para fazer o travejamento ${ }^{4}$ (Figura 4). Até esse ponto da construção, os dois carpinteiros e um ajudante levaram um dia para finalizar essa etapa.

No segundo dia, os carpinteiros montaram, ao longo do comprimento maior da casa, duas peças chamadas de flechais, de madeira castanha-de-rato. Os flechais foram apoiados sobre os pinos. Cada um foi encaixado sobre quatro pinos, delimitando a menor altura do telhado. Sob o pino e o flechal entrou o travessão, ou cruz, no menor comprimento da casa. Foram utilizadas quatro peças paralelas que marcaram a base do elemento chamado de tesoura - o que sustenta o telhado. No meio de cada travessão, formando um ângulo de $90^{\circ}$, uma pequena peça chamada de pontalete, de madeira itaúba, teve a função de erguer a altura desejada do telhado e dar o caimento adequado para as águas da chuva. A grande peça que marca o ponto mais alto da edificação é erguida sob os pontaletes e se chama cumeeira. Para sustentar a cobertura, dezoito peças chamadas de caibro foram dispostas paralelamente e, transversalmente, dez peças chamadas de ripões foram utilizadas para fixar as folhas da telha de alumínio para a cobertura.

No terceiro dia, foi possível fixar as 56 folhas de alumínio e deu-se início à colocação de 31 pranchas de madeira para o assoalho.

Como não há um desenho sobre como será a casa e a organização do espaço interior, é o carpinteiro quem vai comandando a obra, e colocando ali o seu gosto pessoal, seu conhecimento adquirido. Todas as etapas de construção 
são lideradas pelo carpinteiro. O dono da casa só informa se quer sala, o número de cômodos e alguns detalhes decorativos que a esposa prioriza. É o carpinteiro quem molda e deixa sua marca na casa.

Tanto o carpinteiro quanto aqueles que residirão na casa atuam sobre os dados e criam a partir deles, eles têm em suas mãos um conhecimento adquirido pelos seus antecessores, e meios para sua realização, como recursos naturais do contexto ambiental em que vivem e relações sociais que lhe possibilitam realizar o projeto. Sem a rede de relacionamentos que envolve o cotidiano desses moradores de Amanã, a forma da casa seria outra, assumiria outro aspecto visual. A sociabilidade é um dos elementos fundamentais da vida comunitária que direciona todas as ações dentro e fora da casa.

O modelo visual da casa é seguido por quase todos os moradores, com pequenas diferenciações relacionadas mais à estética do que à divisão interna. As casas de Amanã possuem o assoalho suspenso a uma altura de mais ou menos 1 metro do chão, tipo palafita. Num primeiro instante, não consegui entender o porquê desta solução, se a área da comunidade Boa Esperança é considerada terra-firme. Segundo depoimentos dos moradores, somente nas grandes alagações, as casas situadas às margens do lago têm seus barrotes submersos na água. Pude compreender que esse recurso evita umidade nas madeiras e o acesso de bichos de criação no interior da casa, como galinhas, porcos e cachorros. Além disso, as frestas entre uma tábua de assoalho e outra permitem que a dona da casa varra como mais facilidade, para debaixo da casa, a sujeira que ela limpou no seu interior. O tradicional passeio na frente da casa, aos poucos ganha tamanho e forma de uma varanda e ainda pode ganhar uma cobertura e se transformar de fato num lugar para conversar, reunir os amigos no fim de tarde, ou simplesmente para estender roupas em dias chuvosos, uma vez que não há área de serviço nas casas. A casa não apresenta uma volumetria muito expressiva, pois sempre é retangular. Não muito alta, nem imponente. Janelas pequenas, na forma de quase quadrados perfeitos, e dispostas simetricamente. Telhados não muito inclinados, sendo a cobertura feita de alumínio ou telhas de amianto. Não existe quase beiral nas casas, apenas o suficiente para a água não escorrer pela parede. As cores das paredes podem ser brancas, os detalhes dos alisares das portas e janelas de cores vivas, normalmente azuis ou verdes e os assoalhos pintados na cor avermelhada. O que importa para os moradores de Amanã é ter uma casa 
completa, pois isso significa ter sala, cozinha, principalmente, um quarto para o casal e uma área para banho.

\section{$\mathrm{O}$ interior}

Há um plano mental a ser seguido, um modelo preestabelecido Aproveitando o exemplo da construção da casa da comunidade Boa Esperança, presenciei como a família e os envolvidos na obra resolveram a questão interna de como dividi-la em cômodos. O dono da casa relatou que queria uma casa com medidas suficientes para dar mais conforto à família, que se traduzia em um número maior de cômodos. A solução, geralmente, é fazer um prolongamento na forma básica, que é de um quarto ficar de frente para a sala, outro para a cozinha. Caso o morador queira mais cômodos, basta apenas replicar a forma básica a partir de um corredor na parte central.
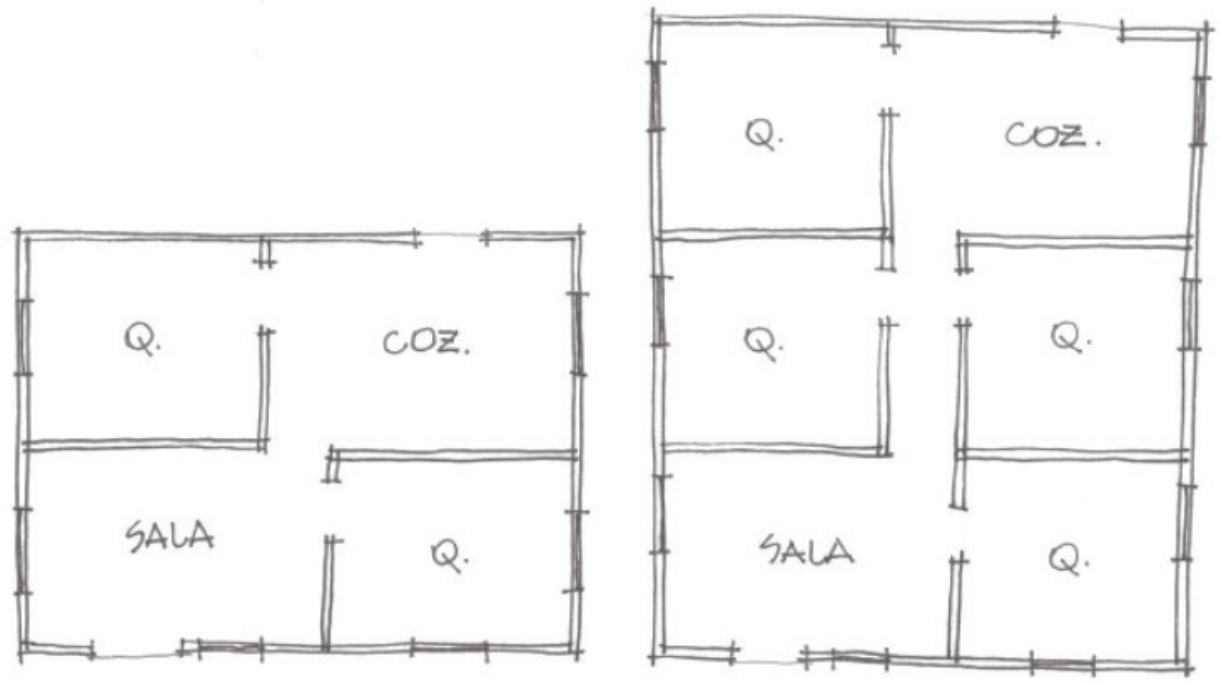

Figura 2 - modelo de planta baixa

O lugar das coisas, que significa o modo e em que lugar os objetos são arrumados e guardados, é uma função de padrões microculturais, representativos, que tornam cada indivíduo um ser único. De acordo com a disposição dos objetos pela casa, eles podem agir como aglutinadores ou 
desagregadores em termos sociais. E, essencialmente, oferecem sentimento de pertencimento. Mas toda esta análise, aparentemente visual, só ganha sentido quando conhecemos quem são as pessoas que ali vivem, e por que dispõem os objetos num lugar e não em outro.

Em contraste com a casa típica apresentado pelo missionário pe. Tastevin (1915) no final século 19 início do século 20, da região do médio Solimões, a casa, atualmente, dos moradores de Amanã apresenta algumas alterações significativas quando ao número de objetos que ali se encontram. Essa casa assemelhava-se a um abrigo improvisado erguido sobre quatro estacas com cobertura de folhas de palmeira. Como Tastevin declara:

Basta abrigar seus instrumentos de pesca e sua espingarda, sua pequena bateria de cozinha e sua louça, composta por panela, dois pratos e um ou dois copos, e um jogo de talheres, tudo colocado aleatoriamente na panela de barro ou em uma caixa. À noite, eles esticam a rede entre duas vigas do tapiri, em cima de um tapete de palha, ou de um elevado de tronco de palmeira. Eles não precisam de mais nada (LIMA et. al., 2006: 256).

Se as pessoas são casadas, essa pequena casa transforma-se em algo maior, em vez de um abrigo improvisado. Basta, então, aumentar as proporções das peças estruturais, acrescentar outras, alongar as dimensões externas da casa, e colocar no interior desta nova uma série de objetos considerados indispensáveis - potes, panelas de alumínio, mais redes, etc. A casa ideal deste morador compreende ter quarto, celeiro, varanda, cozinha e uma parte aberta, o terreiro. Pode parecer tão pobre à primeira vista, mas como sustenta Tastevin, "após um minucioso exame, não falta nada do que é necessário" (LIMA et. al., 2006).

De acordo com a lembrança dos mais antigos moradores, as suas primeiras casas no Amanã eram cobertas de palha, que podiam ser de ubimbranco ou ubim-açu, as paredes de paxiúba - palmeira ou casca de envira, e ainda de ripa de açaí. A divisão interna não existia, eram apenas dois cômodos, sendo um para dormir toda a família e outro para ficar durante o dia.

Poder ter novos bens, em novas quantidades e qualidades, possibilitou a esses ribeirinhos especializarem os espaços que ocupam. A partir de sua 
aquisição, incorporaram novos programas de necessidades e novos cômodos foram criados para atender a funções específicas. A partir dessa mudança, surgiu a necessidade de ter sala, cozinha e, se possível, um cômodo para cada filho.

Internamente, a sala é o primeiro espaço que encontramos (Figura 3). Com medidas maiores do que as antigas, ela abriga na parede de frente para a porta uma estante para televisor e outros pertences da família, que podem ser porta-retratos, livros da escola, alguns brinquedos e enfeites. O televisor chama a atenção, e é posicionado para que não só a família a assista, mas também os vizinhos. A sala é o ponto de encontro. Ela recebe e informa para aquele que chega os novos bens que a família adquiriu. Outro detalhe muito usado para decorar as paredes da sala é o uso de grandes cortinas coloridas. Apesar das janelas serem bem pequenas, esta cortina forra uma das paredes da sala e alegra o ambiente. Quase não se vemos sofás, nem poltronas, todos se acomodam no chão. Porém, quando há um visitante, os moradores oferecem uma cadeira de plástico ou um banco de madeira para sentar.

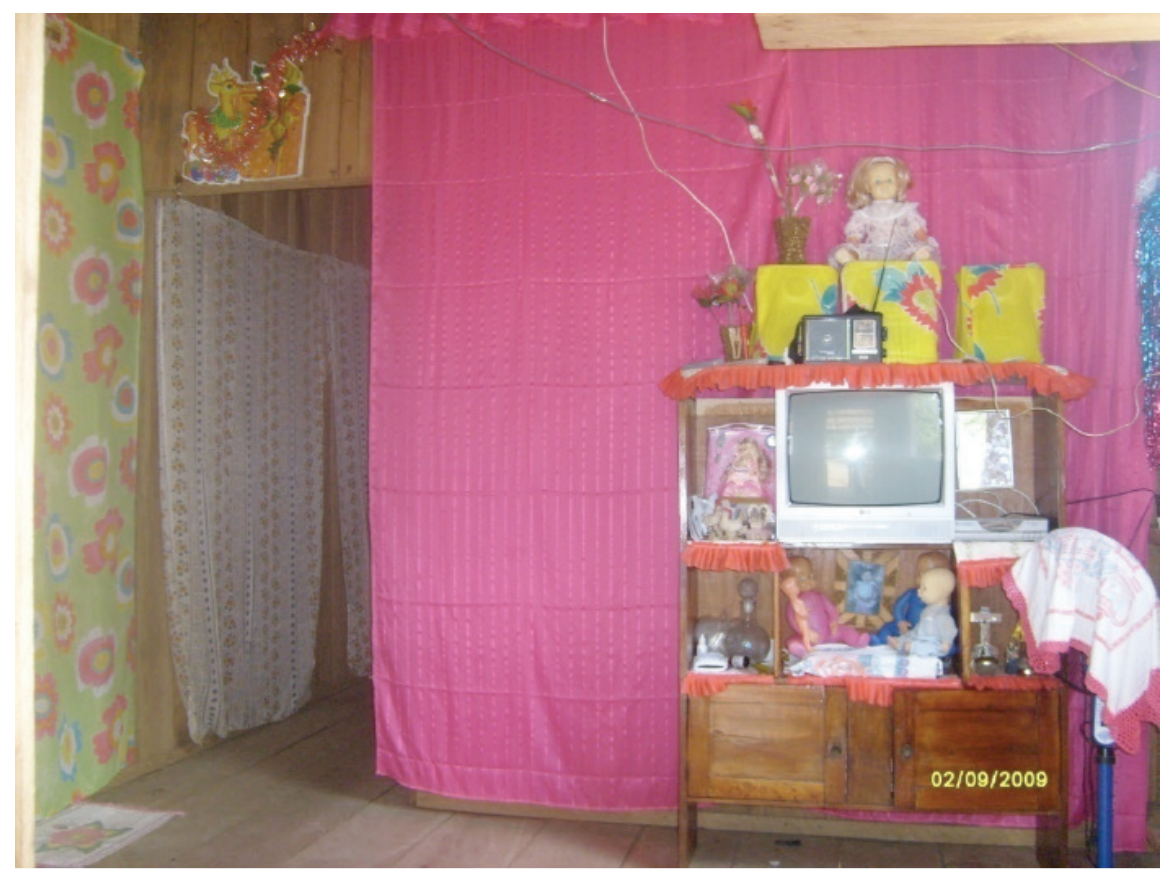

Figura 3 - A sala. 
Quanto ao tamanho dos cômodos, estes podem sofrer também diversas variações. Mas o que se observa é que, normalmente, o quarto do casal é maior, e há espaço pelo menos para uma cama de casal. No outro quarto, o espaço é destinado para redes, podendo ter camas de solteiro, dependendo do número de filhos. Se o casal tiver filhos ainda pequenos, geralmente estes dormem no quarto com eles até por volta da idade de seis anos.

Nos quartos, além de camas ou redes, temos algumas prateleiras de madeiras para guardar roupas, cosméticos e pertences. Os melhores enfeites considerados por eles, geralmente, estão na sala para serem vistos e apreciados. Recordo-me, certa vez, de que durante a estada na morada de um senhor, a todo visitante que chegava e apreciava algum objeto decorativo de sua sala, ele contava a história de sua aquisição. Já aos enfeites da cozinha dizem respeito ao zelo que a mulher tem pela casa. Em ambos os casos, os objetos contam histórias do cotidiano. E apontar para as diferenças e similaridades dos objetos e suas histórias na casa, é um dos caminhos a percorrer a fim de revelar o arranjo social dos objetos.

A cozinha é a parte da casa que mais apresenta objetos utilitários travessas, panelas e tampas - pendurados, normalmente, na parede (Figura 4). Nos ripões, que fixam as tábuas da parede, são apoiados lata de óleo, pilhas, sal e outros elementos que, a qualquer hora, o dono da casa possa precisar. O uso do fogão a gás é um patrimônio visto atualmente nas casas, assim como mesa e cadeiras, e quase todas as casas da comunidade Boa Esperança já possuem um freezer. O rancho pode estar guardado na própria cozinha, dentro de algum armário, no quarto do casal ou sob algumas tábuas que são dispostas em cima das paredes e que funcionam como um sótão.

Alguns objetos e cenas chamaram a atenção por serem constantes nas casas visitadas. Destaco a vassoura de cipó-titica na porta da cozinha; a lata que armazena a farinha que será consumida pela família (a lata condiciona a farinha melhor do que a saca, mantendo-a seca e torrada por mais tempo); o balde de água na entrada da casa; a caldeirada de peixe no fogão; os vários baldes para armazenar água da chuva ou do rio e as travessas e panelas penduradas na parede da cozinha. Essas são imagens que marcam o cenário da vida cotidiana ribeirinha (Figura 5). 


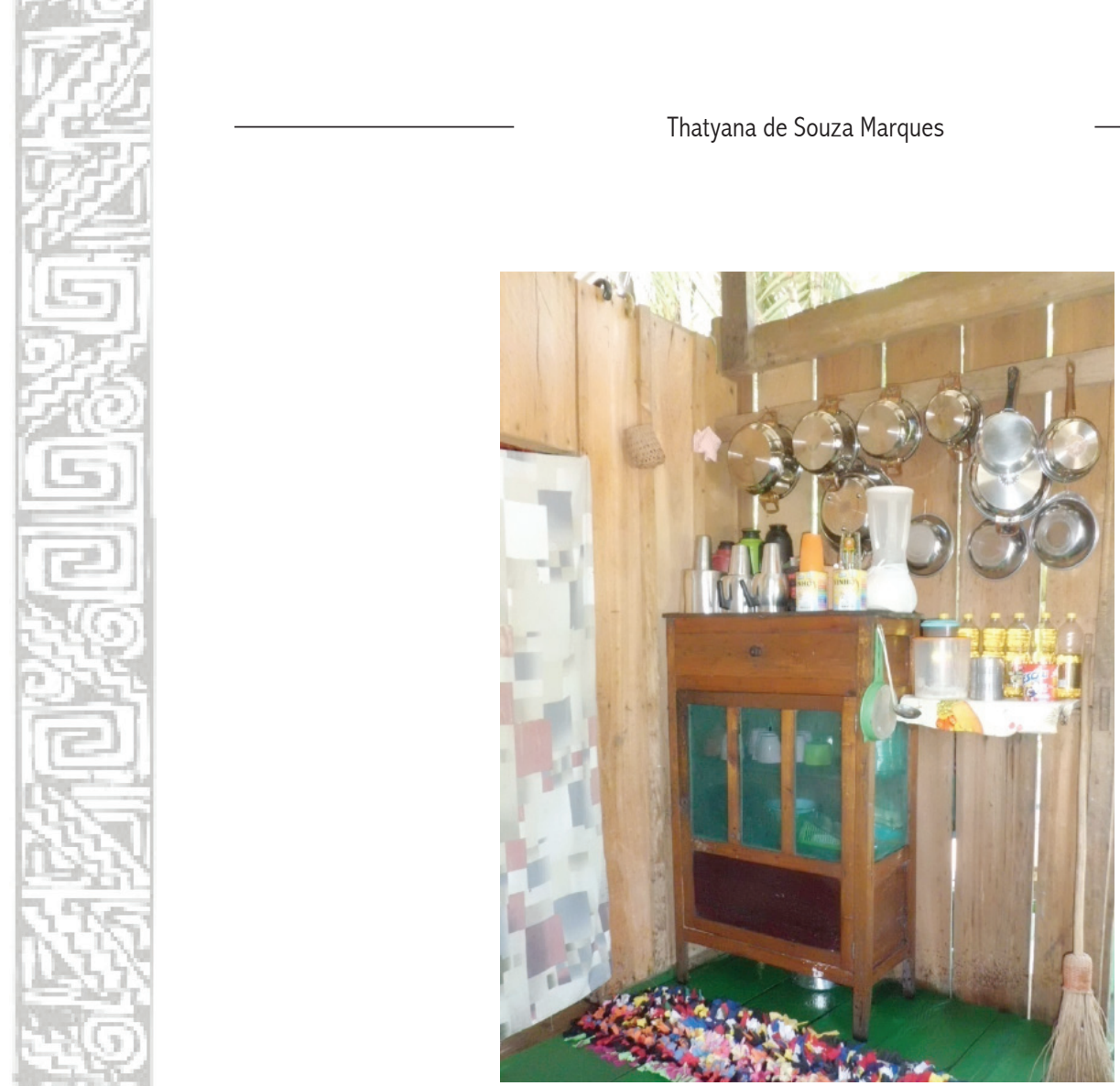

Figura 4 - A cozinha.

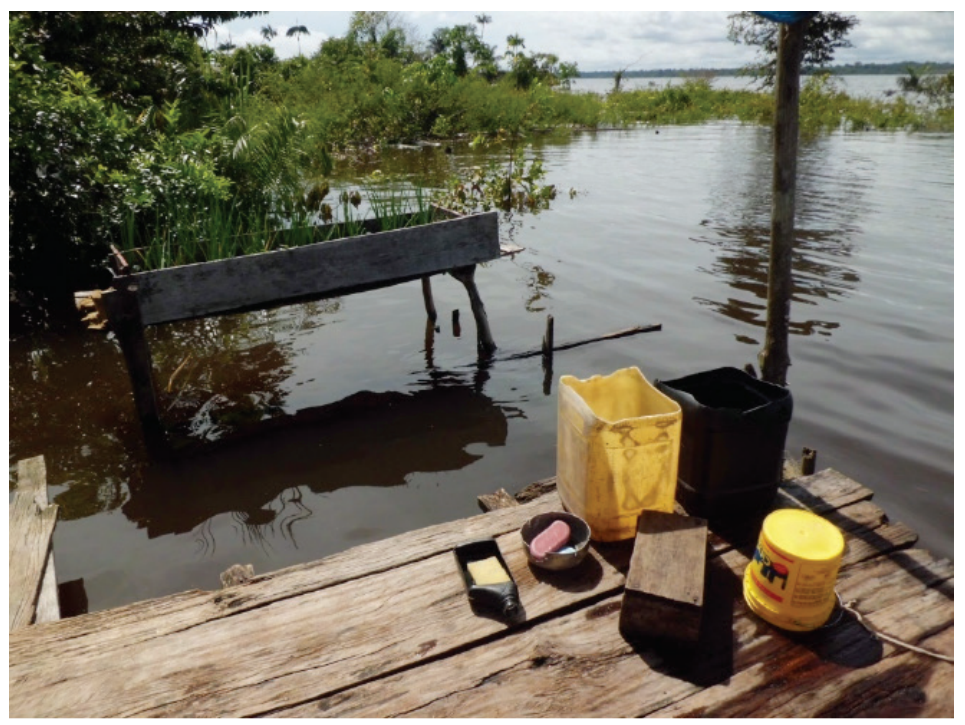

Figura 5 - O jirau de "bubuia" no tempo da cheia. 


\section{A sociabilidade na casa e da casa}

Em trabalho de campo, percebi que as condições para que o espaço arquitetônico adquira o status de lar em Amanã está mais relacionado com as relações sociais que circulam em torno das casas, e que são direcionadas às implicações que a vida em comunidade e as atividades produtivas requerem.

As relações de sociabilidade podem ocorrer por meio da casa e na casa. Os moradores quando indagados o porquê de fazerem uma casa maior, respondiam que era para agasalhar melhor seus convidados:

Melhorou mais para mim porque pelo menos [...] a casa é mais grande quando vem filho da gente com família [...] aí eu tenho onde agasalhar. Porque casa pequena é ruim porque não tem nem onde agasalhar as crianças de noite (depoimento de dona Marlene, comunidade Boa Esperança, 2009).

A gente recebe sempre gente em casa porque gosta, sente necessidade. Eu gosto de estar conversando com as pessoas [...] porque além de eu gostar, a nossa casa, é tipo assim, como coração de mãe, sempre pega mais um (depoimento de um morador da comunidade Juazinho, 2009).

Muitas vezes eu gosto de receber amigos, o pai dela vem às vezes aqui em casa e uma casinha dessa aqui não tem como ele passar muitos dias, aí eu vou fazer uma casa pra nós que tenha um espaço maior que tenha mais cômodo que é pra poder eu chamar ele pra vim, passar uns dias aqui e quem sabe até morar aqui (depoimento de Juliano, comunidade Boa Esperança, 2011).

Uma casa maior possibilita abrigar mais pessoas que não fazem parte do seu grupo doméstico em tempo de festejos, datas especiais ou em momentos de ajuda. Significa reforçar os laços sociais necessários à reprodução social do grupo doméstico, colocando em prática a ideia da reciprocidade.

Soares (2006), com a finalidade de compreender alguns princípios que regem a organização social da comunidade Boa Esperança, atentou para as cenas da vida cotidiana, como por exemplo, a prática do "vizinhar". A autora sugere que existe uma expectativa de ser vizinhado, e que esta é capaz de levar cada grupo a cumprir com seus compromissos, implicando numa 
previsibilidade muito grande de comportamentos:

Eu costumo vizinhar com meu irmão Walmir, com o Francisco que é meu filho, o Assis, [filho], aí, sempre eu mando pra ela [comadre Amazonina], ou eu mando chamar, pra ela comer lá em casa. Mando pro meu irmão mais longe, Manoel, pra Waldisa, ás vezes pra 11,12 pessoas eu mando... Quando é pirarucu, divido uma fatia para cada! Porque é assim, hoje o marido da gente tá pra roça e o vizinho aqui foi pescar, aí ele chega e manda um pedaço pra gente. Quando aquele, naquele dia vai trabalhar, a gente vai pescar e manda pro vizinho. Por isso que o vizinho é bom, porque um dia ele dá pra gente e no outro a gente dá pra ele. É uma coisa assim, quase que emprestado. Agora não é muitos que é assim, não... A gente manda, porque é o dever da gente... $\mathrm{Eu}$ aprendi com o meu pai e a minha mãe, que desde que eu vi meu pai morando perto de vizinho assim, que ele mandava levar as coisas. No Juruá não tinha comunidade, mas tinha uns três vizinhos assim, aí a gente vizinhava ás vezes (agricultora, 53 anos. Entrevista em maio/2005 apud SOARES, 2006: 124).

Lima (2006) aponta o vizinhar como sendo a ação que possui o sentido de trocar coisas entre as casas. Os itens alimentares constituem o principal objeto do verbo vizinhar entre os moradores:

As doações de peixes e caças, as ajudas no trabalho ou trocas de dias, o trabalho de parteiras, e as curas de rezadores, são trocas orientadas pelo princípio da reciprocidade e expressam o modelo ideal de relações sociais horizontais. São caracterizadas por um intervalo entre as contraprestações, e estas são definidas, por um lado, pela necessidade do grupo que a recebe e, pelo outro, pela capacidade do grupo que faz a doação tem para suprila. As trocas não são contabilizadas, nem necessariamente equivalentes. Seus volumes não são definidos por critérios de mercado, e sim pelas regras de reciprocidade do grupo. Fazem parte do código de conduta do que seja uma "boa vizinhança" (LIMA, 2006: 148). 
A rede de trocas que se estabelece entre as casas e as comunidades podem ser vistas como meios sociais de interação. Ter uma boa vizinhança na comunidade e ao seu redor é um fator que possibilita e facilita também a construção da casa.

\section{O sentido social do arranjo}

Retornando, então, ao fio condutor da pesquisa que é a busca pelos elementos e as condições para que um espaço arquitetônico adquira o status de lar, a questão é que os objetos não têm o mesmo significado que, como arquiteta, eu acreditava. A ideia de organizar espacialmente a casa e suas divisões internas não faz parte da concepção de um projeto arquitetônico ribeirinho. Contudo, eles adquirem outros sentidos de organização espacial.

O estabelecimento de um novo grupo doméstico economicamente independente ganha visibilidade quando esse grupo constrói sua primeira casa, mesmo que essa seja próxima à casa dos pais de um dos cônjuges. $\mathrm{O}$ que é satisfatório, uma vez que sua independência não é imediata e implica num processo gradual de separação de seus pais. E ter casa na comunidade implica o direito de uso dos recursos naturais da comunidade: acesso a lagos e a áreas florestais para a caça e extração de produtos florestais madeireiros ${ }^{5} \mathrm{e}$ não madeireiros.

Uma rede de relacionamentos sociais é ativada para tal construção. Vejo a ação que o carpinteiro realiza como a de um bricoleur:

O bricoleur está apto a executar um grande numero de tarefas diversificadas, porém, ao contrário do engenheiro, não subordina nenhuma delas à obtenção de matérias-primas e de utensílios concebidos e procurados na medida de seu projeto: seu universo instrumental é fechado, e a regra de seu jogo é sempre arranjar-se com os 'meios-limites', isto é, um conjunto sempre finito de utensílios e de materiais bastante heteróclitos, porque a composição do conjunto não está em relação com o projeto do momento nem com nenhum projeto particular mas é o resultado contingente de todas as oportunidades que se apresentaram para renovar e enriquecer o estoque ou para mantê-lo com os resíduos de construções e destruições anteriores. O conjunto de 
meios do bricoleur não é, portanto, definível por um projeto (o que suporia, aliás, como com o engenheiro, a existência tanto de conjuntos instrumentais quanto de tipos de projeto, pelo menos em teoria), ele se define apenas por sua instrumentalidade (LÉVI-STRAUSS, 1989: 33).

Enquanto como arquiteta estava presa à ideia de conceber um projeto arquitetônico por meio do conceito de arranjo, percebi que o carpinteiro opera sua ideia através de signos. E esses signos, que ele tem em sua mente, são mensagens de alguma forma pré-transmitidas e que ele coleciona por vivenciála cotidianamente. São as marcas de pertencimento, como por exemplo, a vassoura de cipó-titica, o balde de água na frente da casa, as panelas areadas penduradas na parede da cozinha etc. Lévi-Strauss aponta que o signo é um ser concreto, mas assemelha-se ao conceito por seu poder referencial: um e outro não se referem exclusivamente a si mesmos (LEVI-STRAUSS, 1989).

Assim como o bricoleur, o carpinteiro mantém a célula inicial em sua mente (no caso o modelo do tapiri dos tempos da extração da borracha). A aparência visual da casa e a planta-baixa materializam as relações sociais de Amanã.

Os elementos que hoje representam o cenário são fruto de uma história de ocupação humana vinculada aos tipos de produção econômica que predominaram na região. Se antes as atividades eram mais direcionadas para a extração da seringa, da sorva e na coleta da castanha, atualmente os grupos domésticos se identificam como agricultores. É a principal atividade econômica direcionada para a produção e comercialização da farinha de mandioca, além de ser um item essencial de consumo interno do grupo doméstico. A relação histórica com o local e a distância para as áreas agrícolas são o que os moradores justificam para o estabelecimento da casa na comunidade.

A progressiva melhoria das condições de trabalho em Amanã e a estabilidade das famílias em comunidades resultaram na produção de novas habitações, mas que também estava relacionada a uma maior acessibilidade de objetos. A presença dos objetos está indissociável das condições de habitação e do estatuto de ocupação destas famílias. Se antes havia uma exiguidade do espaço que assumia um caráter provisório de ocupação da área do Amanã (como os tapiris), uma mobilidade, atualmente esse espaço marca uma estabilidade e um pertencimento. 
O sentido social do arranjo (a disposição dos objetos na casa e a própria planta-baixa) é possibilitar a interação entre os residentes e não residentes da casa. Mas o que torna uma casa de moradia para aqueles que a residem é estar inserida neste lugar: o lago Amanã. "Minha casa é aqui dentro" (depoimento de um dos moradores) resume o sentimento de pertencimento à região, que é o elemento que possibilita que este espaço arquitetônico adquira o status de lar. Aqui dentro é a relação com o histórico de ocupação, com o parentesco, com as atividades produtivas, com o viver em comunidade e com a dinâmica ambiental.

Atentar para o contexto no qual está inserido o grupo social foi essencial para compreender essa casa. Não habitamos algo porque simplesmente ocupamos um espaço. Ao invés de insistir ver essa casa sob uma perspectiva funcional da construção, foquei no real significado desse espaço para aqueles que a ocupam. E na medida em que a influência do componente humano prevalece como sendo o centro de valor e a fonte de significado para que o espaço arquitetônico adquira o status de lar, esse passa a incorporar mais as marcas das relações sociais do que as marcas de arranjo.

\section{Notas}

1 Este estudo apresenta resultados parciais da pesquisa de doutorado desenvolvida no Programa de Pós-Graduação Sociedade e Cultura na Amazônia na Universidade Federal do Amazonas (PPGSCA) na Universidade Federal do Amazonas (Ufam), sob a orientação do prof. Dr. Antônio Carlos Witkoski.

${ }^{2}$ Reserva de Desenvolvimento Sustentável - RDS é uma unidade de conservação de uso direto, inclui a população de residentes e usuários no seu processo de implantação, com o objetivo de conciliar conservação e desenvolvimento social, conforme a Lei n.o 9.985 (18/7/2000), que institui o Sistema Nacional de Unidades de Conservação - SNUC.

${ }^{3}$ Elementos que suportam o peso da construção.

${ }^{4}$ Essa peça suporta as pranchas de madeira que irão compor o assoalho da casa.

${ }^{5} \mathrm{O}$ direito à exploração de madeiras para benfeitorias, como a construção de casas nas comunidades, em áreas de Unidades de Conservação, é um direito apoiado por Lei Federal IN n.o 4 (8/9/2009).

\section{Referências}


ALENCAR, Edna Ferreira. Estudos da ocupação bumana e mobilidade geográfica de comunidades rurais da Reserva de Desenvolvimento Sustentável Amanã - RDSA. Tefé, AM: IDSM, 2007, 118 f. (Relatório interno não publicado).

BAUDRILLARD, Jean. O Sistema dos objetos. São Paulo: Perspectiva, 2006, 230 p.

LIMA, Deborah de Magalhães. A economia doméstica em Mamirauá. In: ADAMS, Cristina; MURRIETA, Rui; WALTER, Neves (Eds.). Sociedades Caboclas Amazônicas: modernidade e invisibilidade. São Paulo: Annablume / Fapesp, 2006, p. 145-172.

LIMA, Deborah et. al. Artesanato e Identidade Cultural no Médio Solimões: a promoção de técnicas e conhecimentos tradicionais em comunidades ribeirinhas das reservas Mamirauá e Amanã. Tefé, AM; Belo Horizonte: IDSM / Iphan, 2006, 266 p.

LÉVI-STRAUSS, Claude. O pensamento selvagem. Campinas, SP: Papirus, 1989, $320 \mathrm{p}$.

PEREIRA, Kayo Júlio Cesar et. al.Saber tradicional, agricultura e transformação da paisagem na Reserva de Desenvolvimento Sustentável Amanã, Amazonas. Uakari, v. 2, n. ${ }^{\circ}$ 1, p. 9-26, dez., 2006.

QUEIROZ, H. A criação da Reserva Amanã: um importante estágio para a consolidação do embrião do corredor central da Amazônia. In: AYRES, José Márcio et. al. Os corredores ecológicos das florestas tropicais do Brasil. Belém: Sociedade Civil Mamirauá, 2005, p. 246-249.

SILVA, Elvan. Matéria, ideia e forma: uma definição de arquitetura. Porto Alegre: Editora Universidade UFRGS, 1994, 191 p.

SOARES, Soraia Melissa Failache. Em Boa Esperança:momentos da organização social de uma comunidade da Reserva de Desenvolvimento Sustentável Amanã - AM. Belém: Universidade Federal do Pará / Centro de Ciências Agrárias, 2006, 152 f. (Dissertação de Mestrado). 